\author{
John C. Mitani
}

\title{
Demographic influences on the behavior of chimpanzees
}

\begin{abstract}
Recent research has revealed substantial diversity in the behavior of wild chimpanzees. Understanding the sources of this variation has become a central focus of investigation. While genetic, ecological, and cultural factors are often invoked to explain behavioral variation in chimpanzees, the demographic context is sometimes overlooked as a contributing factor. Observations of chimpanzees at Ngogo, Kibale National Park, Uganda, reveal that the size and structure of the unit group or community can both facilitate and constrain the manifestation of behavior. With approximately 150 individuals, the Ngogo community is much larger than others that have been studied in the wild. We have taken advantage of the unusual demographic structure of this community to document new and intriguing patterns of chimpanzee behavior with respect to hunting, territoriality, and male social relationships. Chimpanzees at Ngogo hunt often and with a considerable degree of success. In addition, male chimpanzees there frequently patrol the boundary of their territory and engage in repeated bouts of lethal intergroup aggression. By forming two distinct subgroups, male chimpanzees at Ngogo also develop social bonds above the level of dyadic pairs. While the sheer number of chimpanzees contributes to differences in hunting, patrolling, mating, and subgrouping at Ngogo, the demographic situation may also constrain behavioral interactions. At Ngogo, male chimpanzees who are closely related genetically through the maternal line do not appear to affiliate or cooperate with each other. Demographic constraints may be responsible for this finding. In this paper, I use these examples to illustrate how the demographic context affects the possible range of behavioral options open to
\end{abstract}

J.C. Mitani

Department of Anthropology, University of Michigan,

1085 South University Avenue, Ann Arbor,

MI 48109-1107, USA

E-mail: mitani@umich.edu

Tel.: + 1-734-7647276

Fax: + 1-734-7636077 individuals and ultimately contributes to the explanation of behavioral diversity in chimpanzees.

Keywords Chimpanzee Pan troglodytes $\cdot$ Behavior . Demography

\section{Introduction}

Variation is a fundamental feature of life (Darwin 1859). Beginning with the very first field studies in the 1960s, it has been evident that there is substantial diversity in the behavior of wild chimpanzees. Seeking explanations for behavioral diversity among chimpanzee populations continues to be a central focus of investigation (Wrangham et al. 1994; Boesch et al. 2002). Toshisada Nishida's long-term fieldwork on chimpanzees at the Mahale Mountains National Park has furnished fundamental insights into the sources of this variability, and his contributions to this body of knowledge constitute a lasting legacy to his pioneering research.

Some of the earliest field studies of primate behavior invoked ecological factors to account for behavioral differences between populations (Jay 1968). For example, comparative work by Nishida and colleagues demonstrated that chimpanzees living at Mahale and Gombe fed on distinctly different foods despite their close geographic proximity (Nishida et al. 1983). Collins and McGrew (1988) subsequently documented considerable habitat variation between Mahale and Gombe, and it is likely that ecological differences in food availability contribute to differences in feeding behavior between chimpanzees at these two sites.

Of late, it has become fashionable for primatologists to invoke cultural factors to account for intraspecific variation in behavior (Whiten et al. 1999, 2001; Fragaszy and Perry 2003; van Schaik et al. 2003). This tradition has a long history at Mahale. Over 25 years ago, McGrew and Tutin (1978) noted that chimpanzees at Mahale adopt a unique posture, the hand clasp, when 
grooming conspecifics. In contrast, chimpanzees at Gombe do not employ this posture during bouts of mutual grooming. Following this initial observation of a potential cultural difference between the Mahale and Gombe chimpanzees, Nishida (1980) described the leafclipping display used by male chimpanzees to solicit matings from females. While characteristic of the behavior of the Mahale chimpanzees, this display has not been observed at Gombe. More recently, dialectal variation in the calls of chimpanzees (Mitani et al. 1992), and social scratching, another distinctive grooming behavior (Nakamura et al. 2000), have been hypothesized as additional examples of chimpanzee cultural behavior.

While ecology and culture constitute two important sources of intraspecific behavioral variation in chimpanzees, the demographic context is often overlooked as a contributing factor. Altmann and Altmann (1979) were among the first to note how demographic parameters such as the size and structure of groups can both affect and be affected by behavior. Demographic variables are now widely regarded as providing the key to understanding behaviors as diverse as dispersal, infanticide, and mating strategies. For example, one hypothesis suggests that the mating system of tamarins is determined by the availability of non-reproductive helpers (Goldizen 1988). In groups lacking non-reproductive helpers, polyandry occurs when mated pairs accept help in the form of another breeding male. Demographic factors have also been hypothesized to play a role in the evolution of female dispersal in primates. In situations where male tenure length in social groups exceeds the time it takes females to mature and start breeding, females disperse to avoid inbreeding with their fathers (Clutton-Brock 1989). Finally infant gorillas become especially vulnerable to infanticide when they are left unprotected by adult males (Watts 1989). In all of these situations, the demographic structure of primate social groups has been implicated to play an important role in affecting behavior.

My own observations of an exceptionally large community of chimpanzees at Ngogo, Kibale National Park, Uganda, have begun to reveal heretofore undocumented aspects of chimpanzee behavior. Several of these behaviors can easily be attributed to the unusual demographic size and structure of the Ngogo community. In this paper, I provide a synopsis of some of our findings that provide new insights into chimpanzee hunting behavior, territoriality, social organization, and male social behavior. I begin with a brief overview of the Ngogo study site and community of chimpanzees.

\section{Methods}

\section{Chimpanzees at Ngogo}

The Kibale National Park in southwest Uganda has been the home to a series of seminal field studies of nonhuman primate behavior (review in Struhsaker 1997). Ghiglieri (1984) was the first to study the behavior of chimpanzees at Ngogo, one of two research sites within the Kibale Park. After a brief hiatus in research, Grieser-Johns (1996) re-initiated field observations of the Ngogo chimpanzees between 1992 and 1993. David Watts visited Ngogo during the summer of 1993 to conduct pilot fieldwork, and in June 1995, I began longterm research there with him (Mitani et al. 2002). Along with Jeremiah Lwanga, four Ugandan field assistants, and North American students, we have maintained continuous observations of the Ngogo chimpanzees since that time (Mitani and Watts 2003).

Ngogo is located in the center of the Kibale Park and straddles the equator at $0^{\circ} 29^{\prime} 89^{\prime} \mathrm{N}$ and $30^{\circ} 25^{\prime} 51^{\prime \prime} \mathrm{E}$. At an altitude of about $1400 \mathrm{~m}$ above sea level, the Ngogo study site lies at an interface of lowland and montane rainforest. While old-growth forest covers most of the study area, human disturbance has created some spots of regenerating forest and Pennisetum purpureum grassland. Butynski (1990), Struhsaker (1997), and Lwanga et al. (2000) provide detailed descriptions of the Ngogo site.

Chimpanzees have been the subjects of intensive behavioral research across their geographic range in Africa (Goodall 1986; Nishida 1990; Boesch and Boesch-Achermann 2000; Matsuzawa 2002). Over 150 person years have been devoted to the study of chimpanzees in the wild, yet we continue to learn a great deal about their behavior. Part of our interest in the behavior of the Ngogo chimpanzees lies in the community's unusual size and structure. With over 20 adult males, 40 adult females and approximately 150 members, the Ngogo community is much larger than others that have been described in nature (Table 1). The demographic structure of the Ngogo chimpanzee community affects their behavior in several important ways.

\section{Results and discussion}

\section{Hunting behavior}

Chimpanzees are well known for their hunting behavior. Initial observations by Goodall (1963) were followed by systematic investigations by several researchers at Gombe (Teleki 1973; Wrangham 1975; Busse 1977, 1978; Stanford et al. 1994; Gilby 2004). Nishida and colleagues (Nishida et al. 1979; Takahata et al. 1984; Uehara et al. 1992; Hosaka et al. 2001) subsequently reported observations of hunting by chimpanzees at Mahale. More recent work at Taï and Ngogo furnishes comparative data on chimpanzee predatory behavior across the African continent (Boesch and Boesch 1989; Boesch 1994a-c; Boesch and Boesch-Achermann 2000; Mitani and Watts 1999, 2001; Watts and Mitani 2002).

The hunting behavior of chimpanzees shows several similarities across sites. Red colobus monkeys (Procolobus badius) are the preferred prey of chimpanzees at all 
Table 1 Intraspecific variation in chimpanzee community size and composition

\begin{tabular}{lrrll}
\hline & Adult males & Adult females & Community size & References \\
\hline Budongo, 1995 & 12 & 14 & 45 & Newton-Fisher (2002) \\
Bossou, 1976-2001 & 2 & 6 & 20 & Sugiyama (2004) \\
Gombe, 1965-1971 & 13 & 12 & 51 & Goodall (1986) \\
Gombe, 1972-1983 & 6 & 16 & 50 & Goodall (1986) \\
Kibale Kanyawara & 9 & 13 & 41 & Wrangham (2000) \\
Kibale, Ngogo & 24 & 48 & 148 & This study \\
Mahale K, 1966-1983 & 4 & 11 & 26 & Nishida et al. (1985) \\
Mahale M, 1980-1999 & 9 & 29 & 79 & Nishida et al. (2003) \\
Tai, 1982-1996 & 7 & 21 & 61 & Boesch and Boesch-Achermann (2000) \\
\hline
\end{tabular}

sites. In some areas where chimpanzees have been studied such as Bossou, Budongo, and Kahuzi-Biega, red colobus monkeys are absent, and hunting is infrequent or rare (Basabose and Yamagiwa 1997; Yamakoshi 1998; Newton-Fisher et al. 2002). Chimpanzees do not hunt red colobus prey uniformly over time. Instead, they often hunt seasonally or during periodic "binges" or "crazes" where hunting effort escalates dramatically to a point where chimpanzees pursue prey nearly every day. Male chimpanzees hunt more frequently and with more success than do females, and hunting success is high, typically exceeding $50 \%$ (Boesch and Boesch 1989; Stanford 1998; Hosaka et al. 2001; Watts and Mitani 2002). The hunting success of chimpanzee predators compares favorably with that of carnivores whose hunting success never exceeds 34\% (Kruuk 1972; Schaller 1972; Caro 1994).

Despite these similarities, differences in chimpanzee hunting behavior exist between and within sites. Chimpanzees at some sites such as Taï and Ngogo expend considerable time and energy actively searching for red colobus prey during hunting "patrols" (Boesch and Boesch 1989; Mitani and Watts 1999). In contrast, chimpanzees at Gombe and Mahale typically meet red colobus monkeys during the course of their normal daily movements and hunt them opportunistically during these chance encounters (Nishida et al. 1979; Stanford 1998). Chimpanzee hunting behavior also varies over time at the same site. At Gombe and Mahale, prey choice and hunting frequency changed as a function of temporal variation in the availability of red colobus prey and number of male chimpanzee hunters. At Gombe, the frequency of predation on baboons decreased and red colobus monkeys increased as chimpanzees met the former less and latter more frequently (Goodall 1986). At Mahale, changes in prey choice and overall hunting effort have taken place. These changes correlated with an increase in the density of red colobus prey and a shift in behavioral observations from the $\mathrm{K}$ to $\mathrm{M}$ group of chimpanzees (Uehara 1997; Hosaka et al. 2001). The K group was small with only four adult males, while the $\mathrm{M}$ group was much larger with nine adult males (Table 1).

Chimpanzees at Ngogo are notable for their hunting behavior. Early research by Ghiglieri (1984) suggested that the Ngogo chimpanzees hunted rarely, but the paucity of observations was likely due to insufficient habituation of subjects. Wherever chimpanzees have been studied, their hunting behavior has been documented only after they have been well habituated to human presence (Goodall 1986; Boesch and Boesch 1989; Uehara et al. 1992; Mitani and Watts 1999). With more work and better habituation of chimpanzees at Ngogo, we now know that individuals there hunt often and as frequently as chimpanzees at other sites (Mitani and Watts 1999, 2001; Watts and Mitani 2001, 2002). During 27 months of observation, hunts at Ngogo occurred about seven times per month (Mitani and Watts 1999; Watts and Mitani 2002). Chimpanzees at Ngogo capture prey in eight out of every ten attempts and are thus unusually successful even by chimpanzee standards (Watts and Mitani 2002).

What accounts for this variability in chimpanzee hunting behavior? In some cases, ecological factors contribute to these differences. For example, changes in prey choice at Gombe and Mahale were clearly linked to temporal variation in the availability of red colobus prey. The relative paucity of hunting at Bossou, Budongo, and Kahuzi-Biega can also be easily attributed to the absence of red colobus monkeys, the preferred prey of chimpanzees. No satisfactory explanation has been proposed for why chimpanzees display different hunting strategies. Here ecological factors may furnish a reason why chimpanzees pursue monkeys opportunistically at some sites and actively during patrols in other places. Hunting patrols are time consuming and energetically expensive and as a result may be undertaken only when ecological conditions permit. Consistent with this, our recent studies indicate that chimpanzees at Ngogo increase their number of hunting patrols and hunting effort during food-rich times (Mitani and Watts 1999, 2001, unpublished data). Herbinger et al. (2001) have argued that feeding conditions at Taï, where chimpanzees live in forested habitats, are much better than at Gombe and Mahale, where chimpanzees occupy open woodlands. Feeding conditions at Ngogo are also undoubtedly good given that the forest there supports such an extraordinarily large community of chimpanzees. These considerations suggest that the hunting strategy employed by the Taï and Ngogo chimpanzees differs from that of Gombe and Mahale chimpanzees 
because of differences in feeding regimes. Hunting patrols take place at Taï and Ngogo given that they can be sustained energetically.

While ecological differences go a long way in helping to account for some of the variability in chimpanzee hunting behavior, demographic factors clearly play a role in explaining other differences. At all sites male chimpanzees are responsible for most hunting, and hunting success typically increases as a function of chimpanzee party size and the number of male hunters (Boesch and Boesch 1989; Stanford et al. 1994; Mitani and Watts 1999; Hosaka et al. 2001). The observed increase in hunting frequency at Mahale can be attributed to the fact that early observations there focused on the relatively small $\mathrm{K}$ group of chimpanzees with only four adult males, while subsequent field work involved the much larger $\mathrm{M}$ group, which possessed twice as many adult male hunters (Table 1). Similarly, the remarkable hunting success of the Ngogo chimpanzees can be explained by the unusual demographic composition of this community. Elsewhere I have hypothesized that male chimpanzees at Ngogo swamp red colobus prey defenses with strength in numbers (Mitani et al. 2002). The Ngogo chimpanzees overwhelm red colobus prey
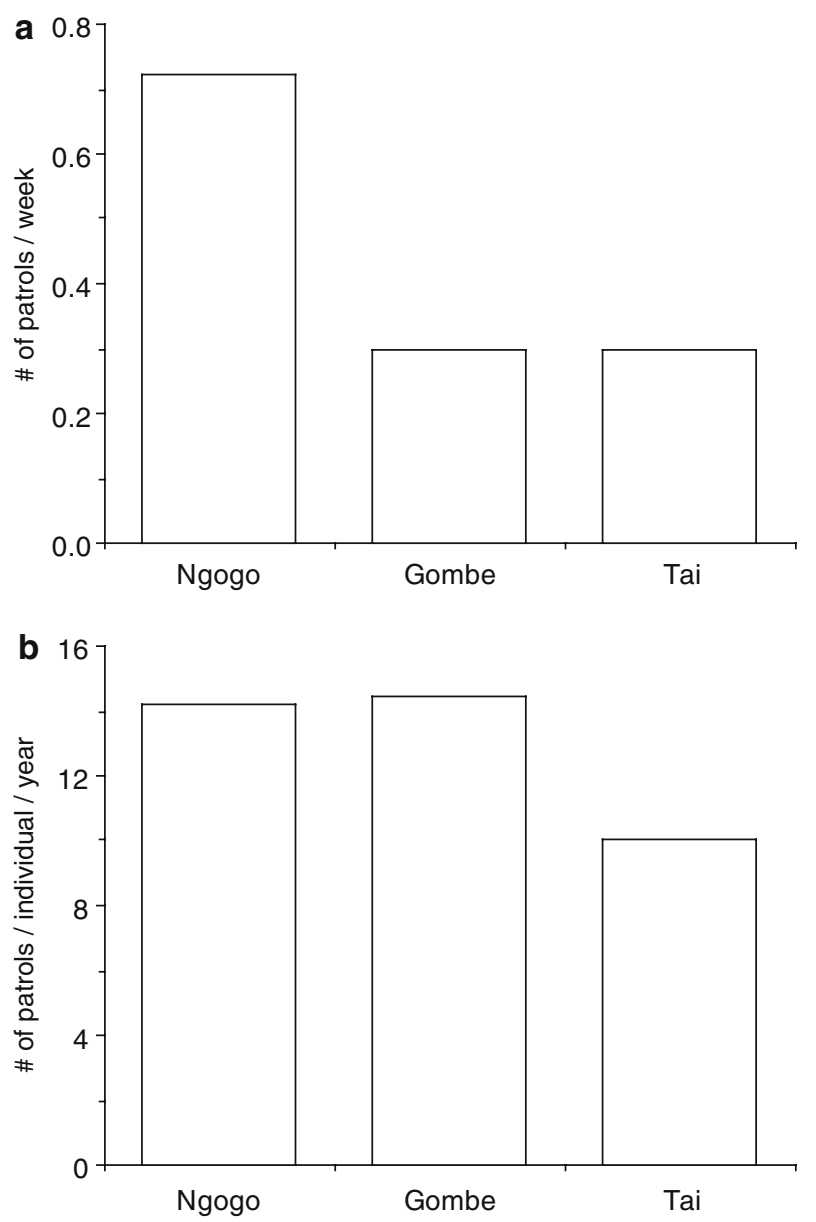

Fig. 1 Intraspecific variation in territorial boundary patrol behavior. a Variation in patrol frequency. b Variation in per capita rates of patrolling with an average of 14 adult male chimpanzees at every successful hunt (Mitani and Watts 1999). Given these factors, it is not surprising that the number of male hunters is the single best predictor of hunting success, and that the success of chimpanzees at Ngogo is atypically high (Mitani and Watts 2005).

\section{Territoriality}

Wherever they live in proximity to conspecifics and have been studied in any detail, chimpanzees have been shown to be territorial. Good descriptions of chimpanzee territorial behavior exist at Gombe, Taï, and Kibale (Goodall et al. 1979; Goodall 1986; Boesch and BoeschAchermann 2000; Watts and Mitani 2001). Like other territorial species, chimpanzees behave aggressively toward individuals who live outside their social groups. Chimpanzees are unusual, however, because intercommunity aggression sometimes escalates to the point where fatalities occur. Lethal intergroup aggression has been documented at several sites, including Gombe, Mahale, Kibale, Budongo, and Taï (review in Wilson and Wrangham 2003).

Boundary patrolling behavior is another distinctive aspect of chimpanzee territoriality (Goodall et al. 1979; Goodall 1986; Boesch and Boesch-Achermann 2000; Watts and Mitani 2001). Male chimpanzees typically perform patrols during which they gather and move in column formation directly to the periphery of their territory. Once there males begin to search for signs, if not contact, with members of other communities. If contact is made, attacks are sometimes launched, with infanticide and cannibalism of victims taking place (Wilson and Wrangham 2003).

Male chimpanzees at Ngogo patrol on average about once every 10 days, a frequency that is much higher than that reported at Gombe or Taï (Goodall 1986; Boesch and Boesch-Achermann 2000; Fig. 1a). In addition to this high rate of patrolling, the Ngogo chimpanzees also engage in lethal bouts of aggression often. During 4 years of observation between 1999 and 2002, we observed the Ngogo chimpanzees kill seven individuals, including four infants, one juvenile, and two adult males (Watts and Mitani 2000; Watts et al. 2002).

Demographic factors are likely to account for the large number of patrols and bouts of lethal aggression that we have observed at Ngogo. Closer inspection of the data reveals that males at Ngogo, Gombe, and Taï patrol with equal frequency on a per capita basis (Goodall 1986; Boesch and Boesch-Achermann 2000; Watts and Mitani 2001; Fig. 1b). Thus, the high rate of patrolling at Ngogo results as a simple consequence of the extraordinarily large number of males there compared with the two other sites. Because patrols sometimes lead to contact between chimpanzees from neighboring groups, it is likely that the frequent fatalities that we have observed at Ngogo can also be attributed to the regular occurrence of patrols there. 
Chimpanzees in the Tai National Park, Ivory Coast, have been observed continuously since 1979, but have been recorded to engage in lethal aggression less frequently than conspecifics at other sites (Wilson and Wrangham 2003; Boesch, personal communication). These behavioral differences may be due to variations in the demographic size and composition of parties. Chimpanzee at Tai associate in larger parties than do chimpanzees at other East African sites (Boesch and Boesch-Achermann 2000). Large parties at Tai may increase the costs of attacking conspecifics there, thus reducing the probability of lethal intergroup aggression.

\section{Social organization}

Nishida (1968) was the first to clarify the social organization of wild chimpanzees. Based on 2 years of observation near a sugar-cane provisioning station at Kasoje in the Mahale Mountains National Park, he noted that chimpanzees live in social groups that he termed "unit groups." Members of these unit groups did not always move together but instead formed temporary subgroups or "parties" (Sugiyama 1968) that constantly varied in

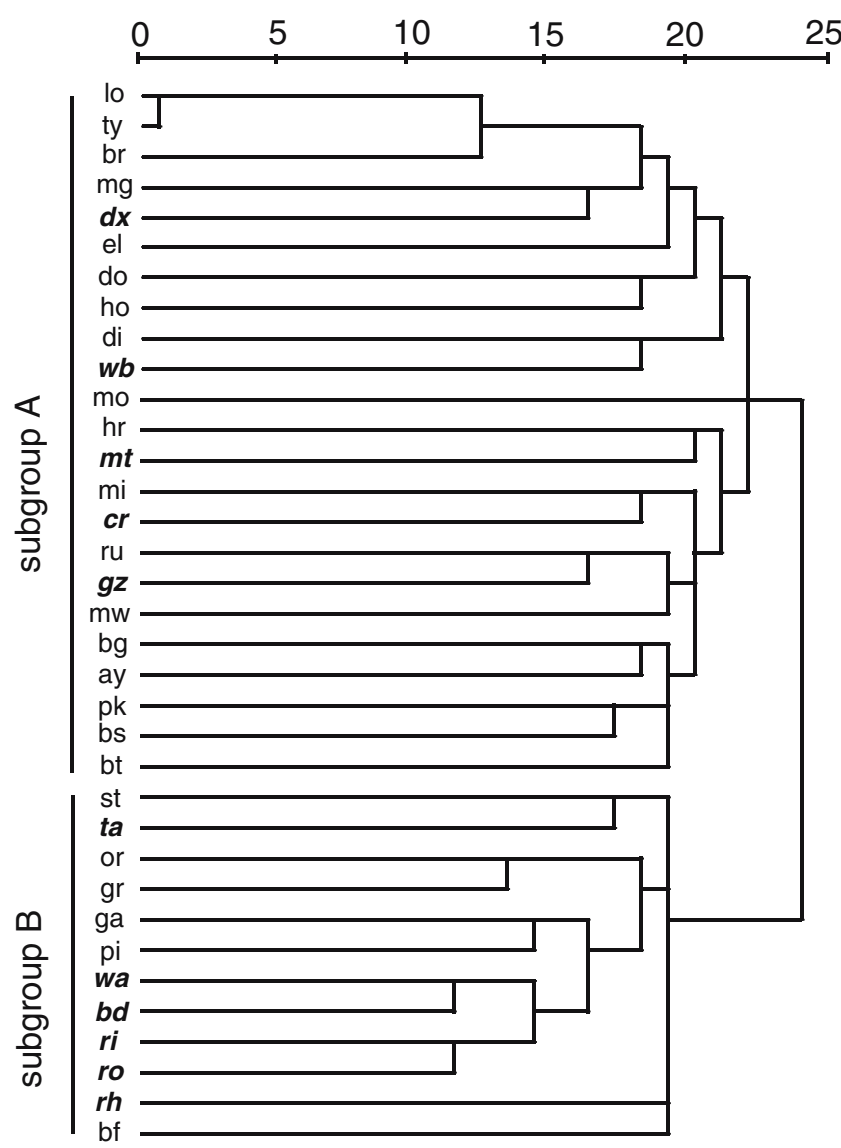

Fig. 2 UPGMA cluster analysis dendrogram of chimpanzee party compositions at Ngogo 1999-2002. Two subgroups of males, A and $\mathrm{B}$ are clearly shown. Plain text adult males. Italics adolescent males (adapted from Mitani and Amsler 2003) size and composition. Despite their temporary nature, parties of chimpanzees did not consist of random aggregations of individuals. During his initial field observations, Nishida (1968) showed that males associated more frequently with each other than do females. Subsequent fieldwork has revealed that male chimpanzee social interactions extend well beyond simple association. Males frequently engage in temporary coalitions and long-term alliances and cooperate in grooming, hunting, meat sharing, and lethal raids on neighboring communities (Nishida 1983; Nishida et al. 1992; Boesch 1994b; Nishida and Hosaka 1996; Wrangham 1999; Mitani and Watts 2001; Watts and Mitani 2001; Watts 2002).

In recent research we have demonstrated that male chimpanzees at Ngogo interact at a level above the dyadic pair, forming subgroups whose members associate predictably (Fig. 2; Mitani and Amsler 2003). Subgroups did not develop along the lines of maternal kinship. Instead, males in each subgroup differed in age, dominance rank, and mating success. Males in one subgroup (subgroup B; Fig. 2) were younger, lower ranking, and achieved lower mating success than individuals in a second, larger subgroup (subgroup A; Fig. 2). Despite this social clustering of males, the Ngogo community shows no signs of splitting. Males in both subgroups continue to share their communal territory and do not display elevated levels of aggression between members.

The unusual demographic size and structure of the Ngogo community is again likely to account for the unusual hierarchical pattern of subgroup formation. With over 35 adult and adolescent males, the Ngogo community is significantly larger than those at other sites. We have suggested that adolescent males will have an extremely difficult time integrating themselves into this unusually large community and have hypothesized that the integrity of the smaller subgroup B is dependent on the behavior of the young, low-ranking males who primarily compose it (Mitani and Amsler 2003). These males gather together socially as they seek to incorporate themselves into the Ngogo community. If this hypothesis is correct, then subgroup membership should be labile and change as adolescent males mature. Testing this hypothesis will require additional observations at Ngogo.

\section{Male social behavior}

Kinship plays an important role in the lives of primates, and chimpanzees are often used to illustrate the effects of kinship on primate social behavior (Silk 2001). As in other primates, enduring bonds form between chimpanzee mothers and their offspring (Goodall 1968, 1986). Male chimpanzees also develop strong social bonds with other males in their own community. These bonds are manifest in several contexts, including association, grooming, proximity, coalitions, meat sharing, 
and territorial boundary patrols. Given the well-known effects of kinship on animal and primate behavior, male bonds among chimpanzees have often been assumed to form between relatives (Riss and Goodall 1977; Goodall 1986; Morin et al. 1994). Two field studies have recently called this assumption into question. In observations of the Kanyawara community at Kibale, Goldberg and Wrangham (1997) showed that male chimpanzees who maintain proximity and groom each other frequently are not necessarily related through the maternal line as assayed by mtDNA haplotype sharing and genetic distances. Our own observations of males at Ngogo support this finding and extend it by revealing that there are no significant relationships between mtDNA genetic relatedness and levels of cooperation, as measured by participation in coalitions, meat sharing, and patrols (Mitani et al. 2000).

These studies raise an unresolved question. If male chimpanzees fail to bias their behavior toward kin, what factors account for the observed patterns of cooperation among them? Here some unusual characteristics of chimpanzee demography and life history provide a potential answer. Chimpanzees live long and reproduce slowly. Because there is an equal sex ratio at birth and relatively high infant and juvenile mortality (Nishida et al. 2003; Wallis 1997; Boesch and Boesch-Achermann 2000; Sugiyama 2004), female chimpanzees will only rarely give birth successively to sons that reach adulthood together. The long interbirth interval in chimpanzees means that successive sons will not often be in a good position to provide useful aid to each other. In sum, males will seldom live with maternal kin who can effectively join them in behaviors that have important fitness consequences. If kin are not available, then males are likely to solicit and use others opportunistically (deWaal 1982; Nishida 1983). Males who belong to the same age cohort may represent particularly attractive social partners because they grow up together, are generally familiar with each other, and share similar social interests and power throughout their lives.

We have recently examined the effects of age on aspects of male social behavior using observations of male chimpanzees at Ngogo (Mitani et al. 2002). Members of the same age cohort cooperated more often than one would expect on the basis of chance (Fig. 3b). Additional analyses replicate earlier findings by showing that males who cooperated frequently were not closely related through the maternal line, as assayed by mtDNA haplotype sharing (Figs. 3a).

\section{Conclusion}

Our observations of the Ngogo chimpanzees reveal that the size and structure of the unit group or community can both facilitate and constrain the manifestation of
Fig. 3 Effects of maternal kinship and age class membership on male social affinity. The number of male dyads $(N)$ that engaged in each of six social behaviors more often than expected by chance were first computed in a social preference analysis. Displayed are the observed and expected percentage of these dyads that: a shared mtDNA haplotypes and $\mathbf{b}$ were members of the same age class. Expected \pm 1 SD values were calculated using a re-sampling technique. ${ }^{*} P<$ sequential Bonferroni $\alpha^{\prime}$ (adapted from Mitani et al. 2002)
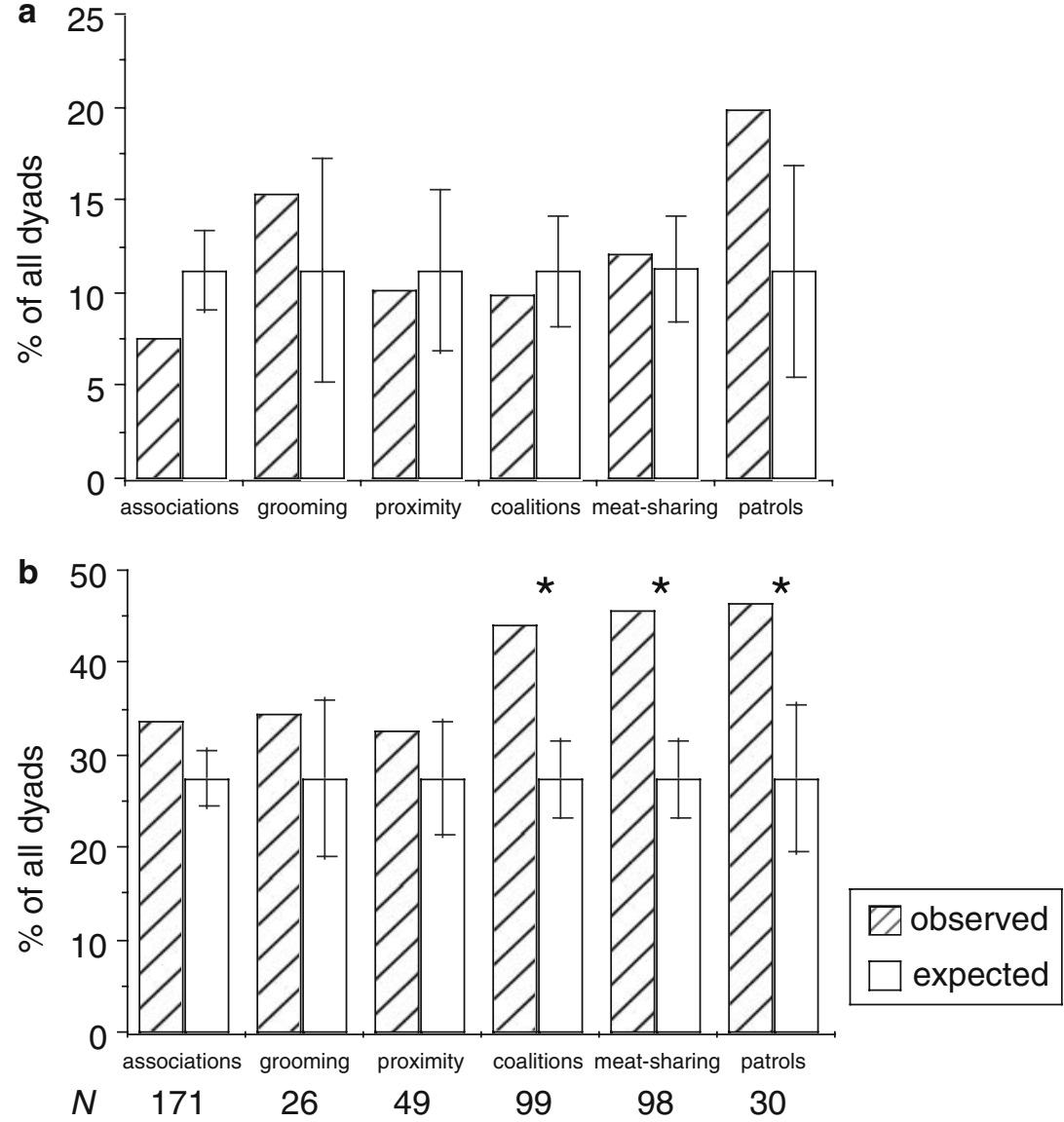
behavior. The demographic context will sometimes provide behavioral opportunities that may otherwise not exist. For instance, the frequency of hunting and territorial patrolling at Ngogo appear to be causally related to the large number of males there. The demographic setting may also lead to the expression of entirely new behaviors, such as male subgrouping behavior at Ngogo. Finally, the demographic milieu will often constrain one's choice of social partners and thereby contribute to observed patterns of social interactions and relationships. Prior research has emphasized the manner in which ecological and cultural factors influence behavioral variations among chimpanzee populations. As the preceding examples illustrate, however, the size and structure of groups affect the possible range of behavioral options open to individuals, and demographic variation within and between communities deserves more careful scrutiny as an important factor contributing to behavioral diversity in chimpanzees.

Acknowledgements Toshisada Nishida furnished me my first opportunity to study wild chimpanzees at Kasoje, and I am indebted to him for giving me that chance and for his subsequent support and encouragement. I am grateful to Juichi Yamagiwa for inviting me to participate in the COE Symposium honoring Toshi on the occasion of his retirement. My fieldwork at Ngogo has been sponsored by the Uganda Wildlife Authority, Uganda National Council for Science and Technology, and the Makerere University. I thank G. I. Basuta, J. Kasenene, and the staff of the Makerere University Biological Field Station for logistic support and three anonymous reviewers for their comments on the manuscript. None of the work that I have conducted at Ngogo would have been possible without the help of my friend and collaborator, David Watts. Our field research at Ngogo has been supported by grants from the Detroit Zoological Institute, L.S.B. Leakey Foundation, National Geographic Society, the NSF (SBR-9253590, BCS0215622), University of Michigan, and Wenner-Gren Foundation to me and L.S.B. Leakey Foundation and National Geographic Society to David Watts.

\section{References}

Altmann S, Altmann J (1979) Demographic constraints on behavior and social organization. In: Bernstein I, Smith EO (eds) Primate ecology and human origins. Garland STPM Press, New York, pp 47-63

Basabose K, Yamagiwa J (1997) Predation on mammals by chimpanzees in the montane forest of Kahuzi, Zaire. Primates $38: 45-56$

Boesch C (1994a) Chimpanzees-red colobus monkeys: a predatorprey system. Anim Behav 47:1135-1148

Boesch C (1994b) Cooperative hunting in wild chimpanzees. Anim Behav 48:653-667

Boesch C (1994c) Hunting strategies of Gombe and Taï chimpanzees. In: Wrangham R, McGrew W, deWaal F, Heltne P (eds) Chimpanzee cultures. Harvard University Press, Cambridge, MA, pp 77-92

Boesch C, Boesch H (1989) Hunting behavior of wild chimpanzees in the Taï National Park. Am J Phys Anthro 78:547-573

Boesch C, Boesch-Achermann H (2000) The chimpanzees of the Taï Forest. Oxford University Press, Oxford

Boesch C, Hohmann G, Marchant L (2002) Behavioral diversity in chimpanzees and bonobos. Cambridge University Press, Cambridge
Busse C (1977) Chimpanzee predation as a possible factor in the evolution of red colobus monkey social organization. Evolution 31:907-911

Busse C (1978) Do chimpanzees hunt cooperatively?. Am Nat 112:767-770

Butynski T (1990) Comparative ecology of blue monkeys (Cercopithecus mitis) in high-density and low-density subpopulations. Ecol Monogr 60:1-26

Caro T (1994) Cheetahs of the Serengeti plains. University of Chicago Press, Chicago

Clutton-Brock T (1989) Female transfer and inbreeding avoidance in social mammals. Nature 337:70-72

Collins DA, McGrew W (1988) Habitats of three groups of chimpanzees (Pan troglodytes) in western Tanzania compared. J Hum Evol17:553-574

Darwin C (1859) On the origin of species by means of natural selection. John Murray, London

deWaal F (1982) Chimpanzee politics. Harper and Row, New York

Fragaszy D, Perry S (2003) The biology of traditions: models and evidence. Cambridge University Press, Cambridge

Ghiglieri M (1984) The chimpanzees of the Kibale Forest. Columbia University Press, New York

Gilby I (2004) Hunting and meat sharing among the chimpanzees of Gombe National Park, Tanzania. PhD thesis, University of Minnesota, Minneapolis, MN

Goldberg T, Wrangham R (1997) Genetic correlates of social behaviour in wild chimpanzees: evidence from mitochondrial DNA. Anim Behav 54:559-570

Goldizen A (1988) Tamarin and marmoset mating systems. Trends Ecol Evol 3:36-40

Goodall J (1963) Feeding behaviour of wild chimpanzees: a preliminary report. Symp Zool Soc Lond 10:39-48

Goodall J (1968) The behaviour of free-living chimpanzees in the Gombe stream area. Anim Behav Monogr 1:161-311

Goodall J (1986) The chimpanzees of Gombe. Belknap Press, Cambridge, MA

Goodall J, Bandora A, Bergmann E, Busse C, Matama H, Mpongo E, Pierce A, Riss D (1979) Intercommunity interactions in the chimpanzee population of the Gombe National Park. In: Hamburg D, McCown E (eds) The great apes. Benjamin/ Cummings, Menlo Park, CA, pp 13-54

Grieser-Johns B (1996) Responses of chimpanzees to habituation and tourism in the Kibale Forest, Uganda. Biol Conser 78:257262

Herbinger I, Boesch C, Rothe H (2001) Territory characteristics among three neighboring chimpanzee communities in the Tai National Park, Cote d'Ivoire. Int J Primatol 22:143-167

Hosaka K, Nishida T, Hamai M, Matsumoto-Oda A, Uehara S (2001) Predation of mammals by the chimpanzees of the Mahale Mountains, Tanzania. In: Galdikas B, Briggs N, Sheeran L, Shapiro G, Goodall J (eds) All apes great and small, vol 1. African apes, Kluwer Academic Publishers, New York, pp 107130

Jay P (1968) Primates: studies in adaptation and variability. Holt, Rinehart, Winston, New York

Kruuk H (1972) The spotted hyena. University of Chicago Press, Chicago

Lwanga J, Butynski T, Struhsaker T (2000) Tree population dynamics in Kibale National Park, Uganda 1975-1998. Afr J Ecol 38:248-257

Matsuzawa T (2002) Chimpanzees of Bossou and Nimba 19762001. Primate Research Institute, Kyoto University, Inuyama, Japan

McGrew W, Tutin C (1978) Evidence for a social custom in chimpanzees? Man 13:234-251

Mitani J, Amsler S (2003) Social and spatial aspects of male subgrouping in a community of wild chimpanzees. Behaviour 140:869-884

Mitani J, Watts D (1999) Demographic influences on the hunting behavior of chimpanzees. Am J Phys Anthro 109:439-454

Mitani J, Watts D (2001) Why do chimpanzees hunt and share meat?. Anim Behav 61:915-924 
Mitani J, Watts D (2003) Field research at Ngogo, Kibale National Park, Uganda, Pan Africa News 10:3-4

Mitani J, Watts D (2005) Seasonality in hunting by nonhuman primates. In: Brockman D, van Schaik C (eds) Seasonality in primates. Cambridge University Press, Cambridge, pp 215-241

Mitani J, Hasegawa T, Gros-Louis J, Marler P, Byrne R (1992) Dialects in wild chimpanzees? Am J Primatol 27:233-243

Mitani J, Merriwether DA, Zhang C (2000) Male affiliation, cooperation and kinship in wild chimpanzees. Anim Behav 59:885-893

Mitani J, Watts D, Pepper J, Merriwether DA (2002) Demographic and social constraints on male chimpanzee behaviour. Anim Behav 64:727-737

Morin P, Moore J, Chakraborty R, Jin L, Goodall J, Woodruff D (1994) Kin selection, social structure, gene flow, and the evolution of chimpanzees. Science 265:1193-1201

Nakamura M, McGrew W, Marchant L, Nishida T (2000) Social scratch: another custom in wild chimpanzees?. Primates 41:237248

Newton-Fisher N (2002) Relationships of male chimpanzees in the Budongo Forest, Uganda. In: Boesch C, Hohmann G, Marchant $\mathrm{L}$ (eds) Behavioural diversity in chimpanzees and bonobos. Cambridge University Press, Cambridge, pp 125-137

Newton-Fisher N, Notman H, Reynolds V (2002) Hunting of mammalian prey by Budongo Forest chimpanzees. Folia Primatol 73:281-283

Nishida T (1968) The social group of wild chimpanzees in the Mahale Mountains. Primates 9:167-224

Nishida T (1980) The leaf-clipping display: a newly discovered expressive gesture in wild chimpanzees. J Hum Evol 9:117-128

Nishida T (1983) Alpha status and agonistic alliance in wild chimpanzees (Pan troglodytes schweinfurthii). Primates 24:318-336

Nishida T (1990) The chimpanzees of the Mahale Mountains. Tokyo Universtiy Press, Tokyo

Nishida T, Hosaka K (1996) Coalition strategies among adult male chimpanzees of the Mahale Mountains, Tanzania. In: McGrew W, Marchant L, Nishida T (eds) Great ape societies. Cambridge University Press, Cambridge, pp 114-134

Nishida T, Uehara S, Nyundo R (1979) Predatory behavior among wild chimpanzees of the Mahale Mountains. Primates 20:1-20

Nishida T, Wrangham R, Goodall J, Uehara S (1983) Local differences in plant-feeding habits of chimpanzees between the Mahale Mountains and Gombe National Park, Tanzania. J Hum Evol 12:467-480

Nishida T, Hiraiwa-Hasegawa M, Hasegawa T, Takahata Y (1985) Group extinction and female transfer in wild chimpanzees in the Mahale Mountains National Park, Tanzania. Z Tierpsychol 67:281-301

Nishida T, Hasegawa T, Hayaki H, Takahata Y, Uehara S (1992) Meat-sharing as a coalition strategy by an alpha male chimpanzee? In: Nishida T, McGrew W, Marler P, Pickford M, deWaal F (eds) Topics in primatology, vol 1. Human origins, Tokyo University Press, Tokyo, pp 159-174

Nishida T, Corp N, Hamai M, Hasegawa T, Hiraiwa-Hasegawa M, Hosaka K, Hunt K, Itoh N, Kawanaka K, Matsumoto-Oda A, Mitani J, Nakamura M, Norikoshi K, Sakamaki T, Turner L, Uehara S, Zamma K (2003) Demography, female life history, and reproductive profiles among the chimpanzees of Mahale. Am J Primatol 59:99-121

Riss D, Goodall J (1977) The recent rise to the alpha rank in a population of free-living chimpanzees. Folia Primatol 27:134-151

van Schaik C, Ancrenaz M, Borgen G, Galdikas B, Knott C, Singleton I, Suzuki A, Utami S, Merrill M (2003) Orangutan cultures and the evolution of material culture. Science 299:102-105

Schaller G (1972) The Serengeti lion. University of Chicago Press, Chicago

Silk J (2001) Ties that bind: the role of kinship in primate societies. In: Stone L (ed) New directions in anthropological kinship. Rowman and Littlefield Publishers Inc., Lanham, MA, pp 71-92
Stanford C (1998) Chimpanzee and red colobus: The ecology of predator and prey. Harvard University Press, Cambridge, MA

Stanford C, Wallis J, Matama H, Goodall J (1994) Patterns of predation by chimpanzees on red colobus monkeys in Gombe National Park, 1982-1991. Am J Phys Anthro 94:213-228

Struhsaker T (1997) Ecology of an African rain forest. University Press of Florida, Gainseville, FL

Sugiyama Y (1968) Social organization of chimpanzees in the Budongo Forest, Uganda. Primates 9:225-258

Sugiyama Y (2004) Demographic parameters and life history of chimpanzees at Bossou, Guinea. Am J Phys Anthro 124:154 165

Takahata Y, Hasegawa T, Nishida T (1984) Chimpanzee predation in the Mahale Mountains from August 1979 to May 1982. Int J Primatol 5:213-233

Teleki G (1973) The predatory behavior of wild chimpanzees. Bucknell University Press, Lewisburg, PA

Uehara S (1997) Predation on mammals by the chimpanzee (Pan troglodytes). Primates 38:193-214

Uehara S, Nishida T, Hamai M, Hasegawa T, Hayaki H, Huffman M, Kawanaka K, Kobayashi K, Mitani J, Takahata Y, Takasaki H, Tsukahara T (1992) Characteristics of predation by chimpanzees in the Mahale Mountains National Park, Tanzania. In: Nishida T, McGrew W, Marler P, Pickford M, deWaal $\mathrm{F}$ (eds) Topics in primatology, vol 1. Human origins. Tokyo University Press, Tokyo, pp 143-158

Wallis J (1997) A survey of reproductive parameters in the freeranging chimpanzees of Gombe National Park. J Rep Fert 109:297-307

Watts D (1989) Infanticide in mountain gorillas: new cases and a reconsideration of the evidence. Ethology 81:1-18

Watts D (2002) Reciprocity and interchange in the social relationships of wild male chimpanzees. Behaviour 139:343-370

Watts D, Mitani J (2000) Infanticide and cannibalism by male chimpanzees at Ngogo, Kibale National Park, Uganda. Primates 41:357-365

Watts D, Mitani J (2001) Boundary patrols and intergroup encounters in wild chimpanzees. Behaviour 138:299-327

Watts D, Mitani J (2002) Hunting behavior of chimpanzees at Ngogo, Kibale National Park, Uganda. Int J Primatol 23:128

Watts D, Mitani J, Sherrow H (2002) New cases of inter-community infanticide by male chimpanzees at Ngogo, Kibale National Park, Uganda. Primates 43:263-270

Whiten A, Goodall J, McGrew W, Nishida T, Reynolds V, Sugiyama Y, Tutin C, Wrangham R, Boesch C (1999) Cultures in chimpanzees. Nature 399:682-685

Whiten A, Goodall J, McGrew W, Nishida T, Reynolds V, Sugiyama Y, Tutin C, Wrangham R, Boesch C (2001) Charting cultural variation in chimpanzees. Behaviour 138:1481-1516

Wilson M, Wrangham R (2003) Intergroup relations in chimpanzees. Ann Rev Anthro 32:363-392

Wrangham R (1975) Behavioural ecology of chimpanzees in Gombe National Park. PhD thesis, Cambridge University, Cambridge

Wrangham R (1999) Evolution of coalitionary killing. Ybk Phys Anthro 42:1-30

Wrangham R (2000) Why are male chimpanzees more gregarious than mothers? A scramble competition hypothesis. In: Kappeler $P$ (ed) Primate males. Causes and consequences of variation in group composition. Cambridge University Press, Cambridge, pp 248-258

Wrangham R, McGrew W, deWaal F, Heltne P (1994) Chimpanzee Cultures. Harvard University Press, Cambridge, MA

Yamakoshi G (1998) Dietary responses to fruit scarcity of wild chimpanzees at Bossou, Guinea: Possible implications for ecological importance of tool use. Am J Phys Anthro 106:283-295 